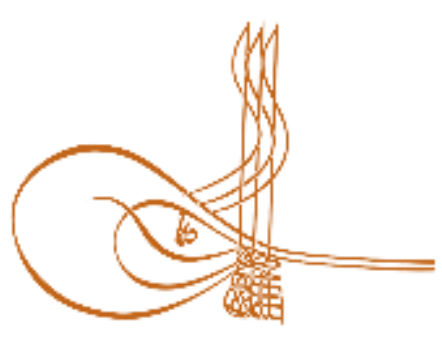

www.turkishstudies.net/social
Turkish Studies - Social Sciences

eISSN: $2667-5617$

Research Article / Araștırma Makalesi

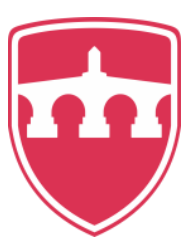

INTERNATIONAL

BALKAN

UNIVERSITY

Sponsored by IBU

\title{
Küresel Kamusal Bir Mal Olarak ABD Hegemonyası
}

The Us Hegemony as a Global Public Good

Yeliz Sarı̈z Gökten*

“Ortaya çıkan sistemi devirmek zor ancak sisteme katılması kolay”

John Ikenberry

\begin{abstract}
US hegemony, embedded in the global capitalist order of the last 75 years can be divided into three periods: The liberal-fordist period, the neoliberal-post fordist period and the non-liberal (illiberal) period that started in 2008 and peaked with Trump. The global capitalist system has sustained itself despite the two World Wars, economic crises, rise and fall of fascism and protectionism. Following the 2008 financial crisis, the requirement of restructuring the system emerged for the existence of the liberal global order. Donald Trump, who was elected US President in 2016, stated that the US would not maintain supply of global public goods, which include many countries and the global population, aiming to satisfy today's needs without endanger the needs of future generations, if the other allies do not share the costs. In his first presidential speech, he used the "America first" motto, which explicitly manifested that the global public goods supplied by the US for the sake of other countries' security and the continuance of the global capitalist order cannot be maintained in conditions are not in favor of the US. By this way, since 1945 the roots of global liberal order and US hegemony which freedom, the rule of law, democracy, common values and international institutions has come under question with Trump. In this study, debates on whether hegemony, which is claimed to be a global public good by Trump and whose procurement may be harmful for the USA, can be seen as a global public good will be carried out. Besides it will be tried to prove that the leadership, which Trump claims to be carried out without any interest, is the key element that makes the US hegemon.
\end{abstract}

Structured Abstract: US hegemony, embedded in the global capitalist order of the last 75 years can be analyzed into three periods: The liberal-fordist period, the neoliberal-post fordist period and illiberal (nonliberal) period. The last period started in 2008 and peaked with Trump's election. The global capitalism has sustained itself despite the two World Wars, economic crises, the rise of fascism. Following the Great Recession of 2008, the necessity of the system reform emerged for the existence of the global capitalist order.

\footnotetext{
${ }^{*}$ Dr. Öğr. Üyesi, Niğde Ömer Halisdemir Üniversitesi, İ̈BF, İktisat Bölümü Asst. Prof. Dr., Nigde Omer Halisdemir University, FEAS, Department of Economics ORCID 0000-0002-6900-9017 yezsarioz@hotmail.com

Cite as/ Atıf: Sarıöz Gökten, Y. (2020). Küresel kamusal bir mal olarak ABD hegemonyası, Turkish Studies - Social, 15(2), 335-347. https://dx.doi.org/10.29228/TurkishStudies.40111

Received/Geliş: 10 December/Aralık 2019

Checked by plagiarism software

Accepted/Kabul: 25 February/Şubat 2020

Published/Yayın: 29 February/Şubat 2020

Copyright (C) INTAC LTD, Turkey

CC BY-NC 4.0
} 
Since 1945, the liberal international order is based on the leadership of the United States. The order was based on the US economy, currency, cooperation with its allies, common norms and global institutions. The liberal international order entered a process of transformation with the election of Trump as President of the United States. The US has clarified that the maintenance of the global order and the security of other countries cannot be sustained in situations which are not in its favor. Thus, the hegemonic system built on liberal order, common rules and international institutions have come under question.

In the US-based world order, the efforts of countries such as China and Russia to integrate into the system and the performance of emerging economies such as Brazil and India have increased the weight of non-western countries in the system. The end of the Cold War with the war-free collapse of the USSR has made the US the sole world power. After 30 years of unrivaled US-based world order entered a transformation process, especially with the 2008 global financial crisis. While the discourse of globalization continues, protectionism, nationalism and regional power struggle have risen. Together with Trump, US hegemony was declared as a global public good.

The presentation of hegemony as global public goods requires redefinition of the concept. Accordingly, hegemony can be defined as the ability of the hegemon to realize the interests of all countries in the system by giving priority to their own interests. Hegemonic power accomplishes this by using force and consent. There are many theories explaining hegemony in global political economy. Hegemonic Stability Theory is the theory that sees hegemony as a global public good. According to this theory, the existence of hegemonic power will ensure the openness and stability of the world order. Since the world order is built by a single power, the existence of the hegemon is the basic condition for monetary stability, freedom of capital movements and a free market. With this perspective, the US provides global public goods to achieve global peace, free market, stability of financial markets and continuation of common rules.

It can be stated that the US hegemony has a different zone of influence since 1945. 2016 is a turning point in terms of both hegemony and liberal order. In 2016, the election of a president who focused on protectionism and nationalism disrupted the country's relationship with its allies led to a major change in US hegemony. Donald Trump's victory is seen as a major threat to the foundations of the international order based on liberal rules. The military and economic power is not the sole premise of the liberal global order. The system has many universal principles, such as freedom, rule of law, tolerance, international institutions and rules. With Trump, these principles have become controversial. Trump was perceived as a threat to the continuity of a liberal and rule-based international order. The policies proposed by Trump are completely opposite to the liberal world order that the US has supported and maintained since 1945.

Trump argues that US hegemony as a global public good harms his country. For him, it is unjustifiable to strive for the maintenance of the liberal order. If other countries do not pay, the US will no longer maintain its hegemony. Trump left the US Trans-Pacific Partnership (TPP) and the Paris Climate Treaty as a result of the slogan "America first". He also stressed the need to renegotiate the NAFTA, which he described as the worst deal in world trade. ree trade, the foundation of Pax America, is restricted by tariffs. It has been decided to impose sanctions on those who move their company to other countries. These developments can be regarded as indications that Trump has taken action against the international liberal order based on globalization and free trade. Addressing businessmen at the APEC summit, as Trump said, "From this day forward, we will compete on a fair and equal basis. We are not going to let the United States be taken advantage of anymore. I am always going to put America first the same way that I expect all of you in this room to put your countries first".

The assumption that hegemony is a global public good lies on the assumption that the world system is anarchic by nature. Hegemon maintains the system in anarchic structure. Does a global public good have to be beneficial for every segment? Theoretically, the answer is yes. However, a public good may not always to the benefit of all. The assertion that the world system is not anarchic reveals that hegemony is a cost element for other countries. The US owes its current position to the hegemony that it has built since 1945 with international institutions and rules. In this sense, the USA is undoubtedly the most beneficiary of the operating of the world system. However, it is understood that the system has entered a new phase and that not a single country can have hegemony. After 2016 it has shown that the supply of global public goods will also be shared as a result of the division of hegemony between countries or alliances.

Keywords: Public Goods, Global Public Goods, US Hegemony, Donald Trump 
Öz: Son 75 yılın küresel kapitalist düzenine gömülenmiş olan ABD hegemonyası; üç döneme ayrılabilir: liberal-fordist dönem, neoliberal-post fordist dönem ve 2008'de başlayan Donald Trump ile zirve yapan liberal olmayan (illiberal) dönem. Küresel kapitalizm iki Dünya Savaşı, ekonomik bunalımlar, faşizmin ve korumacılığın yükseliş ve düşüşüne rağmen kendisini sürdürmeyi başarmıştır. 2008 finansal krizinin akabinde ise liberal küresel düzenin devamı adına sistemin yeniden yapılandırılmasının gerekliliği ortaya çıkmıştır. 2016'da ABD Başkanı seçilen Trump, birçok ülkeyi ve küresel nüfusu kapsayan, gelecek nesillerin gereksinimlerini tehlikeye atmadan bugünkü kuşağın ihtiyaçlarını gidermeyi amaçlayan "küresel kamusal mal"(!) olarak gördüğü hegemonyasının diğer müttefiklerin bedelini paylaşmaması halinde devam etmeyeceğini ifade etmiştir. Trump'ın ilk başkanlık konuşmasında yer alan “önce Amerika” sloganı ile; ABD’nin diğer ülkelerin güvenliği ve küresel kapitalist düzenin devamı için tedarik ettiği küresel kamusal malların ABD lehine olmadığı durumlarda sürdürülmeyeceği net olarak ortaya konulmuştur. Böylece 1945'den beri küresel liberal düzenin ve ABD hegemonyasının dayanakları olan özgürlük, hukukun üstünlüğü, demokrasi, liberal düzen, ortak kurallar ve uluslararası kurumlar Trump'la birlikte sorgulanmaya başlanmıştır. Bu çalışmada Trump tarafından küresel kamusal bir mal olduğu ileri sürülen ve tedarikinin ABD için zararlı olabileceği ifade edilen hegemonyanın küresel kamusal mal olarak görülüp görülemeyeceğine ilişkin tartışmalar yürütülecektir. Ayrıca Trump tarafindan hiçbir çıkar gözetmeksizin yürütüldüğü iddia edilen liderliğin ABD’yi hegemon yapan temel unsur olduğu ortaya konulmaya çalışılacaktır.

Anahtar Kelimeler: Kamusal Mal, Küresel Kamusal Mal, ABD Hegemonyası, Donald Trump

\section{Giriş}

Yaklaşık 75 yıldır liberal uluslararası düzen, ABD’nin gücüne diğer deyiş ile ekonomisine, para birimine, müttefikleriyle işbirliğine, ortak kurallara ve küresel kurumlara dayalı bir biçimde sürdürülmektedir. Liberal uluslararası düzen, Trump'ın ABD Başkanı seçilmesiyle birlikte büyük bir dönüşüm sürecine girmiş, "önce Amerika" sloganı ile küresel düzenin devamı ve diğer ülkelerin güvenliğinin $\mathrm{ABD}$ lehine olmadığı durumlarda sürdürülemeyeceği açık bir biçimde ortaya konulmuştur. Böylece ABD hegemonyasının dayandığı liberal düzen, ortak kurallar ve uluslararası kurumlar üzerine inşa edilen sistem de sorgulanmaya başlamıştır.

Bir taraftan Çin, Rusya gibi ülkelerin sisteme entegre olma gayretleri diğer taraftan Hindistan, Brezilya gibi yükselen ekonomilerin ortaya çıkışıyla birlikte batılı olmayan ülkelerin sistem içindeki ağırlıkları artmaya başlamıştır. Soğuk Savaş döneminin Sovyet Bloğu'nun kansız biçimde dağılması ile nihayete ermesi ABD'yi küresel düzenin tek gücü haline getirmiştir. $\mathrm{ABD}$ merkezli dünya düzeni özellikle 2008 Krizi ile birlikte bir dönüşüm sürecine girmiş; korumacılık, milliyetçilik ve bölgesel güç eğilimleri yükselişe geçmiştir. Trump ile birlikte korumacılık uzun zaman sonra yeniden kendine güçlü bir yer bulmuş, ABD hegemonyası küresel kamusal bir mal olarak ilan edilmiştir.

İlk defa Samuelson (1954) tarafından ortaya konulan kamusal mallar, tüm bireylerin ortaklaşa yararlandığı, bir bireyin tüketiminin diğer bireylerin tüketiminde bir azalmaya neden olmadığı mallar şeklinde ifade edilebilir (s: 387). Kamusal mallar, dışlanamazlık ve rekabetin olmaması açısından iki temel özelliğe sahiptir ${ }^{1}$. Bu açıdan tüketicilerinden biri malı kullanırken bir diğerinin söz konusu maldan kullanımı sırasında mahrumiyet (dışlama) ortaya çıkmaz. Diğer taraftan bir kişinin malı tüketimi başka bir tüketicinin o maldan kullanım miktarını azaltmaz (rakipsizlik) (Ellickson, 1973: 417). Neoliberal düzenle birlikte kamusal mallar da diğer pek çok kavram gibi küresel bir boyut kazanmış; tüketiminde rekabetin olmaması ve dışlanamazlık varsayımlarına ek olarak ülkeler, insanlar, kuşaklar açısından faydalarının evrensel olması ilkesini de kapsar hale gelmiştir (Kaul vd., 1999: 2). Bu bağlamda küresel kamusal bir mal birden fazla

\footnotetext{
${ }^{1}$ Pür ve pür olmayan kamusal mallar ayrımı için bakınız Buchanan (1968), “The Demand and Supply of Public Goods", https://www.econlib.org/library/Buchanan/buchCv5.html (Erişim Tarihi 12.09.2019).
} 
ülkeyi, küresel bir nüfusu kapsamalı ve gelecek nesillerin gereksinimlerini tehlikeye atmadan bugünkü kuşağın ihtiyaçlarını karşılamalıdır (Anand, 2004: 216).

Trump'ın hegemonyayı küresel kamusal bir mal olarak sunması, hegemonyanın da yeniden tanımlanmasını gerektirmiştir. $\mathrm{Bu}$ çerçeveden bakıldığında sistemin istikrarını sağlamak için uluslararası kamusal malların sağlanmasına katkıda bulunan hegemonyayı rasyonel davranış, yardımseverlik veya zorlayıcılık ilkelerinden yola çıkarak tanımlamak yeterli olmayabilir. Bir ülke baskın iktidara dayanarak yalnızca özel çıkarlarını en üst düzeye çıkarmaya çalışırsa davranışları "zorlayıcı" olarak tanımlanır. Bununla birlikte, eğer "toplamın" çıkarlarına, kendi payını kaybetmeden - yani kendi çıkarlarını koruyarak veya artırarak - katkıda bulunursa o zaman "hegemon" olarak adlandırılır. Buradan hareketle hegemon ortak çıkarlar çerçevesinde, çatışma halinde kendi özel çıkarlarını gerçekleştirebilen sistemin bir üyesi olarak tanımlanmaktadır (Min, 2003: 32). ABD’nin 1945'den günümüze dünya düzeninin “devamı adına” arz ettiği hegemonyas ancak bu bakış açısı ile küresel kamusal bir mal olarak görülebilir.

Küresel ekonomi politik teorilerinin temellerinden biri olan hegemonya kavramını küresel kamusal bir mal olarak gören teori Hegemonik İstikrar Teorisidir (HST). Hegemonya teorileri genel olarak Realizm/Neorealizm, Kurumsal Liberalizm ve Eleştirel Ekol çerçevesince ele alınmaktadır. Realist teori hegemonyayı askeri güce indirger ve anarşik olan dünya düzeninde en önemli aktör olarak görülen devlet, sistemin devamı için tek koşuludur. Kurumsal Liberaller, Realist teoriye benzer bir biçimde devleti sistemin merkezine yerleştirir ancak kurumların da sistemde önemli bir konumu olduğuna vurgu yapar. Eleştirel teori ise kendi içerisinde ekollere sahip olmakla birlikte sınıf ilişkilerini öne çıkarır. Bu teorinin en önemli temsilcisi olarak kabul edilen Gramsci, ulusal düzeyde sınıfsal bir hegemonya analizi yapmıştır. Neo Gramsciyenler tarafından bu analiz küresel bir boyuta taşımışlardır. Realizm ve Kurumsal Liberalizmin bir karışımı olan Hegemonik İstikrar Teorisine göre, tek bir egemen gücün varlığ dünya düzeninin dışa açık ve istikrarlı olmasını sağlayacaktır. Dünya düzeni egemen bir güç tarafından inşa edildiği için hegemonyanın varlığı parasal istikrarın, sermaye hareketlerinin serbestliğinin ve serbest piyasanın temel koşuludur ${ }^{2}$. Bu bakış açısı ile liberal küresel düzende barışın sağlanması, serbest ticaret, liberalizm, finansal piyasaların istikrarı ve ortak kuralların devamı adına $A B D$, küresel kamusal bir mal arz etmektedir.

HST'nin temel varsayımlarından hareketle hegemonya, bask1 ve rıza unsurlarını içerecek şekilde, hegemonun kendi çıkarlarına öncelik vererek sistemdeki bütün ülkelerin çıkarlarını gerçekleştirme becerisi şeklinde tanımlanabilir. Aşağıda kamusal mallar üzerinde durulacak arkasından da küresel kamusal bir mal olarak $\mathrm{ABD}$ hegemonyası üzerine tartışmalar yürütülecektir.

\section{1945'ten 2016'ya ABD Hegemonyası}

Son 75 yıldır egemen olan liberal enternasyonalizm, savaş sonrası ABD temelli hegemonik düzene gömülenmiştir. Bu kurumsallaşma, iktisadi açıklık ve güvenlik işbirliği sağlanmasının yanı sıra barış1 korumak, hukukun üstünlüğünü teşvik etmek ve karşıl1klı bağımlılığın yol açtığ1 sorunları yönetmek üzere de kurulan uluslararası kurumların sürdürülebilirliğini amaçlar. Liberal düzenin bu yeni hali ABD ve Avrupa'nın dünya savaşları, ekonomik bunalım, ticaret savaşları, faşizm, totaliterlik ve toplumsal adaletsizlikler gibi dünyayı şoke eden olaylarla mücadele ettiği 20 . yüzyılda doğdu. Büyük Buhran, İkinci Dünya Savaşı ve Soğuk Savaş; eski iktisadi ve politik düzenlemelerin yıkılıp yeni bir sistemin oluşabilmesi için büyük bir olanak sağlamıştır. Savaş sonrası iktisadi, politik, güvenlik politikaları yeniden düzenlenmiş böylece ABD'nin kendi istekleri doğrultusunda şekillendirdiği yeni bir düzen ortaya çıkmıştır. Bu süreçte ABD "özgür dünya" ve bir tür "güvenlik topluluğu" iddiaları ile sisteme giriş yapmış; kurallar, kurumlar, pazarlıklar ile liberal düzenin garantörü misyonunu üstlenmiştir (Ikenberry, 2018: 15; 21-22).

\footnotetext{
${ }^{2}$ Hegemonya teorileri ile ilgili ayrıntılı bilgi için bkz. Sarıöz Gökten, Y. (2013), Hegemonya İlişkilerinin Dünü, Bugünü ve Geleceği: Neo-Gramsci'ci Bir Bakış, Notabene Yayınları, Ankara.
} 
Amerikan hegemonyası fikri Benjamin Franklin dönemine kadar uzanmakla birlikte hayata geçirilmesi II. Dünya Savaşı sonrasına kalmıştır. Bu savaşın sonunda ABD diğer ülkelere iktisadi, politik ve teknolojik üstünlük sağlamıştır. Savaştan en az zarar ile kurtulmayı başaran Amerika, Birleşmiş Milletler, Uluslararası Para Fonu ve Dünya Bankası gibi uluslararası kurumların desteğiyle de hegemon haline gelmiştir (Babones, 2015: 54).

ABD oluşturduğu ortaklıklar, anlaşmalar, kurumlar, pazarlıklar, serbest piyasa, ortak demokrasi ve anti-komünizm propagandası ile bir güvenlik topluluğu oluşturma gayesiyle Batı yönetim sistemini şekillendirmiştir. Nitekim, 1944 ve 1951 arası dönemde ABD kapitalist sistemin en kapsamlı kurumlarını inşa etti. Bu dönemde Birleşmiş Milletler, Bretton Woods, GATT, NATO ve ABD-Japonya ittifakının kurulmasına önayak oldu. Yunanistan ve Türkiye'ye yardım etmek ve Bat1 Avrupa'yı yeniden inşa etmek amacıyla maliyetli yükümlülükler üstlendi. İkinci Dünya Savaşı'nın akabinde tam istihdam ve refah devleti taahhüdü ile sistem yeniden biçimlendirilmiştir. Uluslararası Para Fonu, Dünya Bankası, Gümrük Tarifeleri ve Ticaret Genel Anlaşması ve Avrupa Ekonomi Topluluğu kurularak Avrupa'nın yeniden inşası gerçekleştirildi. Yine aynı amaçla batılı ülkelerin güvenliğini sağlamak adına NATO 1949'da kuruldu. Böylece ABD hem riza hem de güç unsurlarını bir arada kullanarak yeni bir sistem inşa etti (Ikenberry, 2011: 159; Wolf, 2017).

Savaş sonrası kurulan iki kutuplu düzende $A B D$ ve Sovyetler Birliği, kendi düzenlerinin liderleriydi. Her ikisi de dünyanın uzak bölgelerinde liderliğini etkili bir şekilde savunmak için askeri güce, maddi kaynaklara ve kapsamlı bir ideolojiye sahipti. ABD, serbest piyasa, müttefiklerin korunması ve komünist olmayan dünyada istikrarın sağlanması ve desteklenmesine öncülük etti (Ikenberry, 1996: 385). Bu dönemde ABD, küresel politik ve iktisadi düzeni şekillendirmek için elindeki bütün kaynakları harekete geçirmiştir. 1950-1960'larda Amerika'nın petrol rezervleri, Orta Doğu'daki kriz ve ambargolarla tetiklenen küresel düşüşleri telafi etmek için kullanılmıştır. Borç verme düzenlemeleri ve krediler, savaştan hemen sonra İngiliz ticari politikasını etkilemek için kullanılırken, 1950'lerde Avrupa para politikasını etkilemek için dış yardımlara başvurulmuştur. Savaş sonrası kural yapıcı hale gelme ve gerekli kurumları oluşturma çabaları ABD'nin kaynakları ile desteklenmiştir (Ikenberry, 1989: 380-381). ABD bu süreçte hem işbirliği ile rızayı hem de kurallar aracılığı ile baskı unsurlarını bir arada kullanmış; kamusal malların tedariği, kurallara dayalı işbirliği ve karşılıklılık ile hegemonyasını perçinlemiştir. Bir taraftan "komünist Rusya" ile mücadele ederken diğer taraftan Batı ülkeleri arasında serbest ticaret, dışa açıklık gibi liberal uygulamalara dayalı bir sistemi kurgulayıp hayata geçirmiştir (Ikenberry, 2011: 161). ABD, kendisinin öncülüğüne direnmek yerine birlikte çalışmayı istekli hale getirecek açık piyasa ve güvenlik gibi küresel kamusal mallar sağlamıştır (Nye, 2019: 71).

1970'lerle birlikte ABD'nin hegemonya modelinde çatlaklar ortaya çıkmış, işçi hareketleri, ABD'nin Almanya ve Japonya ile olan rekabeti, Vietnam Savaşı'nın maddi manevi yükü ve Petrol Krizi nedeniyle ülkenin gücü aşınmaya başlamıştır. Bu çatışmalara bir yanıt olarak Keynezyen uzlaşı bozulmuş, neoliberalizmin inşasına girişilmiştir (Schmidt, 2008: 73).

1973 Petrol Krizi dünya düzeninin yeniden biçimlenmesine neden olmuştur. Fordizmin yerini alan neoliberal birikim modeli, dünya ekonomisinde üretimin küreselleşmesi ve finansallaşmanın arttırılması olmak üzere iki yapısal gelişme üzerine inşa edilmiştir (Saull, 2012: 331). Neoliberal dönemle birlikte sistemde devletin rolü azaltılırken piyasa kurallarına göre işleyen bir dünya sistemini hayata geçirmek hedeflenmiştir. Yine bu dönemle birlikte post fordist üretim sistemine geçilmiş, esnekleşme sistemin merkezine yerleşmiştir. 1978'den itibaren kapitalist sistem genişlemeye başlamış, Çin, Doğu Almanya ve Rusya sisteme uyum sağlamak adına harekete geçmiştir.

1945 'ten 1991'e kadar iki süper güç, birbirine bağlı olmayan bölgelerde nüfuz oluşturmak için rekabet etmiş ve bir nükleer silahlanma yarışına katılmıştır. Ancak 1989 yılında Berlin Duvarı'nın yıkılması ve 1991 yılında da Sovyetler Birliği’nin çöküşüyle ABD dünyanın tek süper 
gücü haline gelmiştir. ABD askeri gücü küresel ölçekte yansıtabilen tek devlet olduğu için bu dönem tek kutuplu düzen olarak adlandırılmıştır (Nye, 2019: 68).

Soğuk Savaş'ın ardından küresel sistem hızlı bir gelişim göstermiştir. 1990'lı yıllarda dünyada demokrasi ve piyasalar gelişmiş, küreselleşme bir güç olarak kurgulanmış ve ideolojik olarak milliyetçilik gerilemiştir. Neoliberal düzende kurumlar ve sistem hızla evrilmiştir. Rusya yeni düzene ayak uydurmaya çabalarken, Çin de Washington ile stratejik ortaklık sağlamıştır. AB'ye üye ülke sayısı artarken, yükselen ekonomiler olarak adlandırılan ülkeler sisteme daha sık1 entegre olmuşlardır. ABD, Washington Konsensüsü ile sistemdeki tek güç olmuştur (Ikenberry, 2011: 232). Soğuk Savaş döneminde batıda ortaya çıkan bu liberal hegemonik düzen, Soğuk Savaş'ın nihayete ermesiyle birlikte en yüksek yayılım düzeyine ulaşmıştır.

Özellikle Sovyetler Birliği'nin dağılmasından sonra ABD, diğer ülkeler ile karşılaştırılamaz bir askeri, iktisadi ve kültürel güce erişmiştir. Bu süreçte sistem erişebileceği en yüksek küresel düzeye ulaşırken, ABD ekonomisi büyümüş ve borsa yükselişe geçmiştir (Nye, 2002: 233).

Soğuk Savaş’ın bitmesiyle birlikte ABD liderliğinde küresel kapitalizm, tarihindeki en yüksek seviyeye erişmiştir. Komünizme karşı güvenlik işbirliği amacı ortadan kalkarken, sisteme yeni entegre olan ülkelerle birlikte yeni kurumlar ortaya çıkmış ve mevcut kurumlar revize edilmiştir (Ikenberry, 2011: 275).

Neoliberalizm adeta ABD hegemonyasının karşılığı haline gelmiş, ancak son yıllarda durumun değiştiği gözlenmiştir. Kapitalizmin ve modernliğin yükselişinin tarihsel galibi olan güçler, özellikle Kuzey Amerika ve Batı Avrupa ülkeleri, yüksek ekonomik büyüme oranları elde etmek adına mücadele ederken, dünya genelinde yükselen güçler küresel düzenin şeklini değiştirmeye başlamıştır. Çin'in ve Hindistan'ın büyüme oranları, Rusya'nın sisteme dahil olma çabaları, Güney Afrika'nın BRICS ${ }^{3}$ 'in bir parçası olarak yükselmesi ve Yeni Kalkınma Bankası'nın kurulması, Çin'in "Bir Kuşak, Bir Yol” ile Orta Asya'ya uzanan siyasi işbirliği ve altyapı yatırımları atağına geçmesi gibi gelişmeler sisteme yön vermiştir. Özellikle ABD'yi yeniden "büyük yapmak" amacıyla Trump'ın başkan seçilmesi ve akabinde dışlayıcı ve yabancı düşmanı bir siyasi gündemin belirlenmesi, neoliberal düzenden bir kayışa ve küreselleşmenin olası sonuna işaret etmektedir (Regilme ve Parisot, 2017: 3).

2008 Krizi, Amerikan hegemonyasının maddi temelleri olan büyüme ve küresel talebe dayalı neoliberal döngüyü kırmıştır. Sonuç olarak, Amerikan hegemonyasının toplumsal, ideolojik, politik ve kurumsal boyutları olarak neoliberal tarihsel bloğu ciddi şekilde zedelenmiştir (Saull, 2012: 335). 2008 kriziyle birlikte neoliberalizmin ideolojik hegemonyası darbe almış, 1970'lerde Bretton Woods Sistemi'nin çöküşünün ardından güçlenen neoliberalizm sorgulanmaya başlamıştır (Rucki, 2011: 335). Bir taraftan Çin ve Hindistan gibi ülkelerin yüksek büyüme oranları diğer taraftan yükselen ekonomiler, G20, BRICS gibi oluşumlar ABD'nin gücünün aşındığına dair emareleri güçlendirmiştir. Bununla birlikte ABD liberal küresel düzeni devam ettirebilmek adına faaliyetlerini sürdürmüştür. 2016 yılında Trump'ın Başkan seçilmesi ABD hegemonyası için bir dönüm noktasını temsil eder. Trump ile birlikte Amerika'nın liberal hegemonyasının dayanakları olan dişa açıklık, çok taraflı ticaret, gömülenmiş liberalizm, uluslararası kurumlar ile evrensel normlar tartışılmaya başlanmıştır. Nye'a göre (2019) ABD gücünün dayandığı iktisadi ve askeri güç, demokrasi ve insan hakları söylemleri ile küresel ortaklıkların korunması ilkeleri henüz geçerliğini kaybetmemekle birlikte sallantıdadır (s: 71). Bir sonraki bölümde Trump ile birlikte ABD hegemonyasının değişen yapısı ortaya konulmaya çalışılacaktır.

\footnotetext{
${ }^{3}$ BRICS; Brezilya, Rusya, Hindistan, Çin ve Güney Afrika'nın baş harflerinin bir araya gelmesiyle oluşmuştur.
} 


\section{ABD Hegemonyasında Dönüm Noktası Olarak Donald Trump}

II. Dünya Savaşı sonrası ABD’nin inşa ettiği Pax Americana'nın aşınma sürecine girdiği açıktır. Bu anlamda Trump'ın sürdürdüğü agresif politikalar bu gerileme sürecinin nedeni değil aslında bir sonucu şeklinde yorumlanabilir. Ülkede gelir eşitsizliği, reel gelirdeki düşüş, imalat sektöründe dışa bağımlılık, verimlilik artışında yavaşlama ABD'deki orta sınıfın altını oymuştur. Ayrıca, dünyanın ekonomik ağılık merkezlerinin Avrupa'dan Asya'ya kayması, Batı'nın beş asırdır süren küresel baskınlığını sekteye uğratmaktadır (Layne, 2018: 89-90).

Liberal dünya düzeni değişim sürecindedir. Batılı ülkelerde eşitsizlik ve işsizlik arttıkça korumacılık ve milliyetçilik ön plana çıkmış, liberal düzen tartışılmaya başlanmıştır (Duncombe ve Dunne, 2018: 41). Refahın ülkeler arasında paylaşılmasını sağlayan iktisadi açıklık, toplumlar arasında demokrasiyi ve eşitliği sağlayan politik açıklık ve iktisadi-politik açıklığın karşılıklı etkileşimiyle toplumsal refah artışı üzerine kurgulanmış olan ABD hegemonyası Trump ile birlikte biçim değiştirmeye başlamıştır (Sullivan, 2018: 15).

ABD'nin Irak ve Afganistan'daki politik yenilgisi, 2008 krizi, Çin gibi küresel bir rakibin varlığı, Rusya ve İran gibi ülkelerin yeniden güç kazanma çabalarının bir sonucu olarak tek kutuplu düzen yerini çok kutuplu düzene bırakmaktadır. Trump ile, ülkenin yeniden güçlenme hamleleri korumacılığa dayandırılmaya başlanmıştır (Smith, 2018).

2016'da ABD'de milliyetçilik ve korumacılığa odaklanan ve ülkenin müttefikleriyle arasını açan bir başkanın seçilmesi, yaklaşı 75 yıllık liberal düzenin büyük bir değişim sürecine girmesine yol açmıştır. Donald Trump'ın seçilmesi, liberal kurallara dayalı uluslararası düzenin temellerine karşı büyük bir tehdit olarak görülmektedir. Liberal küresel düzenin tek dayanak noktası askeri ve iktisadi güç değildir. Sistemin özgürlük, hukukun üstünlüğü, hoşgörü, uluslararası kurumlar ve kurallar gibi pek çok evrensel dayanağı bulunmaktadır ki Trump ile bu ilkeler sorgulanır hale gelmiştir. 2008'den beri büyük ölçüde aşınan ABD merkezli küresel düzenin çökeceği savı, Trump'ın sistemin yapıtaşlarına dokunacağı iddiaları ile yeniden alevlenmiştir (Nye, 2019: 67; Stephens, 2016). Trump'ın önerdiği politikalar, ABD'nin 1945'ten beri desteklediği ve sürdürdüğü liberal dünya düzeniyle ters düşecek niteliktedir (Layne, 2018: 89).

20 Ocak 2017'deki konuşmasında Trump, artık yeni bir vizyonla ülkeyi yöneteceklerini ve bugünden itibaren ilk önceliğin Amerika olacağını ilan etmiştir. "Önce Amerika... Dünya milletleriyle dostluk ve iyi niyet arayacağız, ancak tüm milletlerin kendi çıkarlarını öncelikli olarak ortaya koyma hakkı olduğu anlayışını taşıyoruz" açıklamasında bulunmuştur. Ayrıca Trump; ticaret, vergiler, göçmen politikaları ve dış ilişkilere dair alınacak her kararın Amerikalı işçilere ve ailelere fayda sağlamak adına verileceğini ifade etmiştir. Korumacılığın geri geleceğini ve böylece ABD gücünün tekrar sağlanacağını savunmuştur (Trump, 2017a). Başkanlık konuşmasında Trump, gerekli hallerde liberal küresel düzenden vazgeçerek ve agresif politikalara başvurarak ABD'yi "ABD'yi yeniden büyük yapmak" amaciyla hareket edileceğini duyurmuş, bu bağlamda uluslararası düzeyde "önce Amerika" sloganı ile hareket edileceğini ilan etmiştir. Trump'ın dış politikalara dair açıklamasında küresel yapılanmanın ve serbest kullanıcı (free rider) uygulamasının son bulacağını ifade etmiş, böylece II. Dünya Savaşı öncesi söylemlere geri dönmüş̧tür. Bu durumu, "koruduğumuz ülkelerin savunma maliyetini ödemeleri gerekmektedir eğer ödemezlerse kendilerini savunmaya hazırlıklı olmaları gerekir" şeklinde ifade etmiştir (Posen, 2018: 20).

Ayrıca dünya düzeninde güvenliği sağlamak adına ABD'nin katlandığı maliyetlere, ticari kayıplara ve parasal yüklere son verileceğini ifade etmiştir (Norrlof, 2018: 63). Trump konuşmasında; ABD'nin ulusal çıkarlarının öncelikli olacağı, IŞíD’e karşı Rusya ve Suriye ile ortak hareket edileceği, Avrupalı müttefiklerin "serbest kullanıcı" olmasının önüne geçileceği, Asya ile ticari ilişkilerin tekrar gözden geçirileceği ve Çin'in para biriminin yeniden değerlemeye zorlanacağ 1 ifade edilmiştir (Trump, 2017a; Ignatius, 2016). 
Trump'ın açı1ış konuşmasında serbest ticarete, kurumlara ve anlaşmalara duyulan güvensizliğe vurgu yapması, ABD'nin II. Dünya Savaşı'nın sonundan günümüze oynadığı liderlik rolünü terk edeceği endişesini uyandırmıştır. Bazı çevrelerce Trump'ın ABD'nin hegemon olduğu dönemdeki dış politikasına, en korkulan sıfat olan "izolasyonist" yakıştırması yapmıştır (Posen, 2018: 20). Trump'a göre, Amerika'nın küresel liberal düzenin en tepesindeki konumu ülke için büyük dezavantajlara neden olmaktadır. Ona göre ABD'nin uluslararası sistemdeki mevcut rolü, firsatlardan ziyade büyük engeller içermektedir. $\mathrm{Bu}$ rol, $\mathrm{ABD}$ için kendisinin sömürülmesine yol açan özel bir sorumluluktur. ABD vatandaşlarının dış tehditlerden korunması ve ülkedeki yaşam standartlarının yükseltilmesi yerine liberal dünya düzenini sürdürmeye çabalamak gereksizdir (Norrlof, 2018: 70).

Bu anlamda Trump, 1945'den itibaren ABD'nin liberal politikalara karşı hareket eden ilk başkan olmuştur. Trump'a göre yıllardır Amerikan endüstrisi pahasına dış sanayi zenginleştirilmiş, orta sınıfın refah seviyesi gerilemiş ve bu refah kaybı tüm dünyaya yeniden dağıtılmıştır. $\mathrm{Bu}$ anlamda ABD sınırlarının, diğer ülkelerden ve şirketlerin yıkıcı politikalarından korunması gerekmektedir. O’na göre korumacılık büyük refah ve güç sağlayacaktır (Trump, 2017a).

Trump'ın başkanlığıyla birlikte Avrupa Birliği'nin dağılması teşvik edilmiş ve küreselleşmeyi tersine çevirmeyi hedefleyen iktisadi milliyetçilik savunuları alevlenmiştir. ABD bu süreçte TPP'den ve Paris İklim Antlaşması'ndan ayrılmış, Trump tarafindan dünya ticaretinin en kötü anlaşması olarak ilan edilen NAFTA'nın yeniden müzakere edilmesinin gerekliliği vurgulanmıştır. Pax America'nın temeli olan serbest ticarete tarifeler konulmuş ve şirketini diğer ülkelere taşıyanlara yaptırımlar uygulanmasına karar verilmiştir. Bu gelişmeler Trump'ın küreselleşme ve serbest ticarete dayalı uluslararası liberal düzene karşı harekete geçmiş olduğunun göstergeleri olarak kabul edilebilir (Stokes, 2018: 137). Vietnam'ın Danang kentinde Asya-Pasifik Ekonomik İşbirliği Zirvesi (APEC) zirvesinde işadamlarına seslenen Trump, "Bugünden itibaren adil ve eşit bir temelde rekabet edeceğiz. Amerika'dan istifade edilmesine artık izin vermeyeceğiz" ifadelerini kullanmıştır (Trump, 2017b).

Trump küresel düzende çok tarafl1lı̆̆ 1 reddederek yerine fayda-maliyet ekseninde iki taraflılı̆g1 savunmuştur. Ülkeler arasındaki bu iki taraflılık, Amerika'nın hareket özgürlüğünü engelleyici ya da kısıtlayıcı bütün hamlelerden uzak olmalıdır. Buna göre "dünya küresel bir topluluk değil, ulusların, sivil toplum kuruluşlarının ve işletmelerin avantaj sağlamak için rekabet ettiği bir arenadır" (Stokes, 2018: 137). Aslında 1987 yılında CNN'de yaptı̆̆ konuşmada Trump, Japonya ve diğer ülkelerin ABD üzerinden avantaj sağladığını ve ABD'nin desteğini kötüye kullandığını, ABD’nin müttefiklerine sağladıkları güvenlik için bir bedel/karşılık almasının bütün ülkelerin lehine olacağını açıkça ifade etmiştir. O'na göre bu yersiz harcamaların çiftçiye, hastalara ve evsizlere kanalize edilmesi daha anlamlı olacaktır (Trump, 1987).

Donald Trump, korumacılık politikasının bir parçası olarak Ocak 2018'de, güneş panellerine ve çamaşır makinelerine yüzde 30 ila 50 oranında gümrük vergileri koymuştur. Aynı yıl ABD çoğu ülkeye çelik ve alüminyum ürünleri için sırasıyla \% 25 ve $\% 10$ tarife uygulamıştır. Bu tarifeler 1 Haziran 2018'de, Avrupa Birliği, Kanada ve Meksika'yı kapsayacak şekilde genişletilmiştir. Ayrıca, 6 Temmuz'da Trump yönetimi, Çin'den 50 milyar dolar değerinde ithal edilen 818 ürün kategorisine yeni tarifler belirlemiştir. Şubat 2019'da Trump, Pekin'le arasındaki ticaret müzakerelerinde kaydedilen "önemli ilerleme" sonrasında 200 milyar dolarlık Çin ithal mallarına uygulanacak tarife artışını erteleyeceğini açıklamıştır. ABD'nin Çin ile ticari görüşmelerinde fikri mülkiyet haklarının koruması, teknoloji transferi, tarım, hizmet, para birimi gibi pek çok konuda önemli ilerlemeler kaydedildiği ifade edilmiştir. Yine Trump yönetimi, çok taraflı ve bölgesel ticaret anlaşmalarını iki taraflı anlaşmalarla değiştirme hedefini açıkça vurgulamıştır. Yapılacak ticaret anlaşmalarının iki taraflı gerçekleştirileceği ve eğer anlaşmaya uyulmazsa anlaşmanın feshedileceği ifade edilmiştir (Norrlof, 2018: 67). 
Trump'ın, ABD'nin geleneksel stratejisinden önemli bir açıdan saptığı ifade edilebilir. 1945 'den itibaren ABD, dünyadaki en güçlü devlet olmayı hedeflemesi açısından hegemonik ve uluslararası sistemi çok taraflı kurumlar tarafından düzenlenen kurallara dayalı bir sisteme dönüştürdüğü ve piyasa odaklı olduğu için liberaldi. ABD'nin bu hedeflerinden sapan Trump, "liberal hegemonyadan" "liberal" kavramını çıkartma gayretindedir. Trump, tamamen "yeniden büyük ABD” stratejisi olarak liberal olmayan hegemonyayı benimsemiştir (Posen, 2018: 20).

Trump'ın illiberal hegemonya stratejisini düzensiz uygulaması ve burjuvazi tarafindan bütünüyle desteklenmemesi ABD emperyalizminin göreceli düşüşünü tersine çeviremedi ve hatta birçok yönden hızlandırdı. Trump'tan önceki Amerikan yönetimleri, dünya düzeninde hegemon olabilmek adına hem rıza hem de zor kullandılar. Amerika'nın çıkarlarının peșinden gitmek için WTO'dan IMF'ye ve NATO gibi kuruluşların yanı sıra kültürel, askeri ve ekonomik güçlere başvurdular. Trump'ın bu tür kurumlara yönelik şüphesi ve sert güce odaklanması, müttefiklerini yabancılaştırdı ve gücüne meydan okunmasına neden oldu (Smith 2018).

ABD sistemin devamı adına gerçekleştirdiği küresel kamusal bir mal olarak hegemonyasını devam ettirmemekle ülkeleri tehdit ederken en büyük rakibi olarak görülen Çin barışçıl yaklaşımlar sergilemektedir. 2018 Haziranında Xi Jinping Şangay İşbirliği "ben merkezli ve dar görüşlü" olarak nitelediği korumacılığa karşı "daha açık bir dünya ekonomisi” açıklamaları yaparken; Trump $G 7^{4}$ Bildirisi'ni reddetmiş ve ABD müttefiklerine tarifeler koyarak "kurallara dayalı uluslararası düzen" savunusu yapmıştır. Xi Jinping ise 10 Haziran'da gerçekleştirilen Qindao Şangay İşbirliği Organizasyonunda "WTO kurallarına uymalı ve çok taraflı ticaret sistemini desteklemeliyiz, böylece açık bir dünya ekonomisi oluşturmalıyız" şeklinde açıklama yapmıştır (Nye, 2019: 67; Moody, 2018).

Çin'in, dünyanın en büyük ikinci ekonomisi haline gelmesini sağlayan unsurlar küresel kapitalizme kontrollü eklemlenmesi, ABD ile işbirliği ve Dünya Ticaret Örgütü'ne dahil olmasıdır. Xi Jinping Davos'daki konuşmasında (2017); dışa açık bir politika benimsemenin ve küreselleşmenin bütün ülkeler açısından pozitif toplamlı olacağını ifade etmiştir. Bütün ülkelerin birbirine bağlı bir büyüme elde etmesini ve refahı paylaşmasını sağlamak adına küreselleşmenin arttırılmasını, küresel serbest ticaret ve yatırımlardaki artışın teşvik edilmesini ve korumacılığa son verilmesini savunmuştur. Korumacılığın karanlık bir odaya kendini kilitlemek gibi olduğunu; rüzgar ve yağmurun girmesini engelleyebileceğini ancak bunun 1şıktan ve havadan mahrum kalma pahasına gerçekleştiğini ifade etmiştir. O'na göre ticaret savaşlarında kimse kazanamaz.

Xi Jinping'in küresel uluslararası sistem hakkındaki yorumları, Çin'in ABD'nin yerini devralmayı planladığının bir göstergesi olarak yorumlanmıştır. Ancak Xi'nin gerçekte işaret ettiği şey, Trump'ın yol açtığı olumsuz iklimden yararlanmaktan ziyade Çin'in küresel sistemde kısa vadeli radikal bir değişim istememesidir (Sullivan, 2018: 12).

Trump'ın Çin'e yaklaşımı beş yıl önce Asya-Pasifik eksenini doğuran bakış açısından keskin biçimde ayrılmaktadır. ABD, Çin ile olan ittifakını güçlendirmek yerine bölgeyi daha çok kendi kaderine terk etmiş durumdadır. Trump'ın bu hamlesi aslında "müttefiklerini potansiyel tehditlere karşı kendi güvenlikleri için ödeme yapmaya zorlama" söylemiyle tutarlıdır (Lin, 2016: 7-9).

Savaş sonrası oluşturulan liberal hegemonik düzenin temelleri sarsılmaktadır. Bu süreç en basit ifade ile gücün dağılımında ve sonuçlarında ortaya çıkan bir değişimdir. ABD ve müttefikleri savaş sonrası düzendeki güçlerini kaybetme sürecindedir. Tek kutuplu düzenin sonuna gelinmiş, çok merkezlilik ortaya çıkmışır. Avrupa ve Japonya'nın güçlerinin gerilemesiyle birlikte bu üçlünün küresel düzendeki güçleri de aşınmaktadır. $\mathrm{Bu}$ süreçte Çin'in sistemdeki konumu tartışılmakla birlikte, Çin muhtemelen ABD'yi illiberal bir hegemon haline getirmeyecek ve

${ }^{4}$ G7 ülkeleri; Almanya, ABD, İngiltere, Fransa, İtalya, Japonya ve Kanada'dan oluşmaktadır. 
küresel Güney muhtemelen ABD’nin önderliğindeki düzenine doğrudan meydan okuyan jeopolitik bir blok olarak ortaya çıkmayacaktır. Ancak $\mathrm{ABD}$ ve eski müttefikleri küresel düzenin daha küçük bir parçası olmaya devam edecek ve bu liberal uluslararası düzeni destekleme ve savunma yeteneklerini kisitlayacaktır (Ikenberry, 2018: 17).

Özellikle 2017'den itibaren Amerika'nın yumuşak gücünde yaşanan erozyon uluslararası düzenin geleceğini giderek belirsiz hale getirmektedir (Stiglitz, 2017). ABD hegemonyas1 küreselleşme, uluslararası rekabette egemenlik ve siyasi güce odaklanan ABD emperyalizminin bir projesi olarak kabul edilebilir. İktisadi ve jeopolitik çıkarları gerçekleştirmek adına askeri güç de hegemonyayı desteklemektedir (Harris, 2003: 68). Amerika'nın liderliği, dünya genelinde siyasi ve ekonomik istikrarın sağlanması için gerekli kamusal mallarının üretilmesinde önemli bir unsur olarak görülmektedir.

Günümüzde liberal uluslararası düzen veya Pax Americana terimleri, ABD'nin dünyadaki konumu açıklamada kullanılmaz hale gelmiş olmakla birlikte ülkelerin dünya düzeninin devamı adına küresel kamusal mal gereksinimi devam etmektedir (Nye, 2019: 79).

\section{Sonuç}

Trump tarafindan barış, demokrasi, serbest piyasa, güvenlik ve iktisadi istikrar küresel düzenin devamı adına ABD tarafından tedarik edilen kamusal mallar olarak kabul edilmiştir. $\mathrm{Bu}$ malların arz edilmesinin ABD'nin aleyhine olduğu ve pek çok ülkenin hiçbir karşılık ödemeden bu mallara sahip olduğu ileri sürülmüştür. $\mathrm{Bu}$ bakış açısına göre $\mathrm{ABD}$ açıkça sömürülmektedir. $\mathrm{Bu}$ nedenle ülke, dış tehditlerden korunmalı ve yaşam standartlarının yükseltilmesi ana hedef olmalıdır. Liberal dünya düzeninin devamı adına verilen çaba yersizdir. Bu bağlamda Trump tarafından atılan adımlar ABD hegemonyasının göreli gerileyişinin önünü alamamıştır.

Trump öncesi ABD hegemonyası Gramsci'nin ifade ettiği üzere baskı ve rıza unsurlarına dayanmaktaydı. ABD gücünün devamı adına, WTO'dan IMF'ye ve NATO'ya kadar uluslararası kuruluşların desteğini almış, kültürel, askeri ve iktisadi güçleri bir arada kullanmayı başarabilmiştir. Trump'ın bu tip kurumlara şüpheci yaklaşımı ABD'nin hegemonyasını daha çok baskı unsurlarına dayandırmasına yol açmış, müttefikleri ile arasını açmıştır.

Aslında Trump'ın başkan adayı olmasından çok önce uluslararası düzenin dağılmakta olduğuna yönelik iddialar bulunmaktadır. Ortak kurallar ve uluslararası kurumların gücü aşınırken, teknolojinin ve küreselleşmenin etkisiyle ülkelerin gördüğü zararlar artmış, büyük güçler ile diğerleri arasındaki güç ve etki açığı her geçen gün kapanmaya başlamıştır. Soğuk Savaş'ın bitişiyle tek kutuplu düzenin baş aktörü olan ABD özellikle 2008'den sonra sistemdeki mevcut konumunu yitirme sürecine girmiştir. Öyle görünüyor ki yeni düzende sistemin daha küçük bir parçası olmaya razı olmakta, liberal uluslararası düzeni destekleme ve savunma yetenekleri sınırlı kalmaktadır.

Pax Americana'nın erozyonunun önemli bir göstergesi, uluslararası kurumsal düzenin eski aktörlerinin zayıflamasıdır. IMF ve Dünya Bankası'nın Çin'e (ve ortaya çıkan diğer önemli piyasa ekonomilerine) daha fazla oy gücü verilmesi için reform talepleri, BM Güvenlik Konseyi üyeliğini genişletme yönündeki baskılar, 2008'de G8'in Çin, Hindistan, Endonezya ve Güney Afrika dahil olmak üzere gelişmekte olan ülkelerin eklenmesiyle G20'nin oluşturulması, Asya Altyapısı Yatırım Bankası'nın (AIIB) kurulması, BRICS birlikteliği, Şangay İşbirliği Teşkilatı ve Avrasya Ekonomik Birliği ile Yeni Kalkınma Bankası'nın kurulması, Bir Kuşak Bir Yol girişimi dünya düzeninde değişimlerin habercisidir (Layne, 2018: 99-100). AIIB ve Bir Kuşak ve Bir Yol ile Çin Pax Americana'ya sadece jeopolitik değil, uluslararası iktisadi liderlik ve uluslararası kurumlar açısından da meydan okumaktadır. Böylece ABD’nin sistemdeki gücü aşınırken Çin en azından yumuşak güç açısından küresel düzende konumlanmaktadır. 
ABD artık küresel kamusal malların tedariki konusunda gönülsüzdür. Trump küresel kamusal bir mal olarak hegemonyanın ülkeye zarar verdiğini ileri sürmektedir. Ancak hegemon olan ülkenin kamusal mallar sağladığ1 ve bunu gerçekleştirirken zarar gördüğü savı gerçekçi değildir. Trump'ın ileri sürdüğü gibi küresel kamusal bir mal olarak sistemin devamını sağlayan hegemonya aslında ABD'nin dünya düzeninde oluşturmayı hayal ettiği ve bunu gerçekleştirmek adına gayret sarf ettiği bir güçtür. Aslında ABD'nin dünya düzenindeki mevcut konumu, 1945'den beri oluşturduğu hegemonyasının bir sonucudur.

Hegemonyanın küresel kamusal bir mal olduğu savının temelinde dünya sisteminin doğası gereği anarşik olduğu varsayımı yatar. Anarşik yapıda sistemin devamı hegemon ile mümkündür. Peki, küresel kamusal bir malın her kesim için yararlı olması gerekir mi? Teorik olarak bu sorunun cevabi evettir. Ancak kamusal bir mal her zaman her kesimin yararına olmayabilir. Örneğin bebeklere yapılan rota virüsü aşısının bulunmuş olması tüm toplumların yararına olarak kabul edilebilir. Ancak toplumdaki bütün bebeklerin rota virüsünden etkilenme olasılığ düşüktür. Böyle bir durumda rota aşısının bütün bebeklere yapılması rota virüsünden etkilenmeyecek bebekler için ilave maliyet halini alabilir. Buradan hareketle dünya sisteminin anarşik olmadığının kabulü aslında hegemonyanın kendisinin bir maliyet olduğunu ortaya koyar. 1945'den günümüze dünya sisteminden en karlı çıkan ülke kuşkusuz ABD'dir. Ancak 2016 sonrası göstermiştir ki, veri koşullar altında dünya düzeni tek bir ülke hegemonyası altında ilerleyemez. Öyleyse yeniden biçimlenen düzende hegemonyanın paylaşılmasının bir sonucu olarak küresel kamusal malların tedariki de ülkeler arasında paylaşılacaktır.

Pax Americana'nın, küreselleşmenin sona ermesiyle veya çatışmalarla çözülüp çözülmeyeceği, küresel düzenin sürdürülmesinde büyük rol oynayan özellikle Çin ve Hindistan gibi batılı olmayan güçlerin yeni dönemde söz sahibi olup olmayacağı merak konusudur. Bu cevap büyük ölçüde batılı ülkelerce verilecektir.

\section{Kaynakça}

Anand, P.B. (2004), "Financing the Provision of Global Public Goods", World Economy, Vol. 27, No. 2, 215-37. DOI: https://onlinelibrary.wiley.com/ doi/abs/10.1111/j.14679701.2004. 00597.x

Babones, S. (2015), "The Once and Future Hegemon", The National Interest, No. 138, 54-62.

Buchanan, J. M. (1968), "The Demand and Supply of Public Goods", https://www.econlib.org/library/Buchanan/buchCv5.html (Erişim Tarihi: 12.09.2019).

Duncombe, C. ve T. Dunne, (2018), “After Liberal World Order”, International Affairs 94: 1, 2542; DOI: https://doi.org/10.1093/ia/iix234

Ellickson, B. (1973), "A Generalization of the Pure Theory of Public Goods", The American Economic Review, Vol. 63, No. 3 (Jun., 1973), 417-432.

Harris, J. (2003), "Transnational Competition and the End of U.S. Economic Hegemony", Science \& Society, Vol. 67, No. 1, 68-80.

Ignatius, D. (2016), 'What President Trump's Foreign Policy Will Look Like', Washington Post, 9 Nov., https://www.washingtonpost.com/opinions/global-opinions/what-president-trumpsforeign-policy-will-looklike/2016/11/09/3ab88670-a63211e6ba59a7d93165c6d4_story. html?utm_term=.b8cf2a46b2fb. (Erişim Tarihi: 16.10.2019).

Ikenberry, G.J. (1989), "Rethinking the Origins of American Hegemony", Political Science Quarterly, Vol. 104, No. 3, 375-400. 
Ikenberry, G.J. (1996), “The Future of International Leadership”, Political Science Quarterly, Vol. $111,385-402$.

Ikenberry, G.J. (2011), Liberal Leviathan, The Origins, Crisis, and Transformation of the American World Order, Princeton University Press.

Ikenberry, G.J. (2018), “The End of Liberal International Order?", International Affairs, 94: 1 (2018) 7-23. DOI: https://doi.org/10.1093/ia/iix241

Jinpin, X. (2017), Davos World Economic Forum, Jinping, Xi. https://www.weforum. org/agenda/2017/01/full-text-of-xi-jinping-keynote-at-the-worldeconomic-forum. (Erişim Tarihi 12.11.2019).

Kaul, I., Grunberg, I. ve Stern, M.A. (1999), Global Public Goods: International Cooperation in the 21st Century, Oxford University Press, Oxford.

Layne, C. (2018), "The US-Chinese power shift and the end of the Pax Americana", International Affairs 94: 1, 89-111. DOI: https://doi.org/10.1093/ia/iix249

Lin, S. (2016), "The Public Costs of Grand Strategy in The Trump Era", World Affairs , Vol. 179, No. 3, 4-23. DOI: https://doi.org/10.1177/0043820016689516

Min, B.W. (2003), "Understanding International Hegemony: A Complex Systems Approach", Journal of International and Area Studies, Vol. 10, No. 1 (June 2003), 21-40.

Moody, A. (2018), "Shanghai Spirit", China Daily: European Weekly https://search.proquest.com/docview/2055302586/4637D194A1D24794PQ/1?accountid=1 6645 (Erişim Tarihi: 13.03.2019).

Norrlof, K. (2018), "Hegemony and Inequality: Trump and The LiberalPlaybook", International Affairs 94: 1 (2018) 63-88. DOI: https://doi.org/10.1093/ia/iix262

Nye, J.S. (2002), “The American National Interest and Global Public Goods”, International Affairs, Vol. 78, No.2 , 233-244.

Nye, J. (2019), “The Rise and Fall of American Hegemony from Wilson to Trump", International Affairs 95: 1, 63-80. DOI: https://doi.org/10.1093/ia/iiy212

Posen, B. (2018), “The Rise of Illiberal Hegemony: Trump's Surprising Grand Strategy," Foreign Affairs, 97(2): 20-27.

Regilme, S. ve Parisot J. (2017), "Debating American Hegemony: Global Cooperation and Conflict", American Hegemony and the Rise of Emerging Powers: Cooperation or Conflict, Edited By S. Regilme ve J. Parisot, Routledge Press., 1-17.

Rucki, S. M.(2011), "Global Economic Crisis and China's Challenge to Global Hegemony: A NeoGramscian Approach", New Political Science, Volume 33, Number 3, September, 335-355. DOI: https://doi.org/10.1080/07393148.2011.592022

Samuelson, P. (1954), "The Pure Theory of Public Expenditure", The Review of Economics and Satistics, Vol. 36, No.4, 387-389.

Sarı̈z Gökten, Y. (2013), Hegemonya İlişkilerinin Dünü, Bugünü ve Geleceği: Neo-Gramsci'ci Bir Bakış, Notabene Yayınları, Ankara.

Saull, R. (2012), "Rethinking Hegemony: Uneven Development, Historical Blocs, and the World Economic Crisis", International Studies Quarterly, Vol. 56, No. 2, 323-338. DOI: http://doi.org/10.1111/j.1468-2478.2012.00720.x. 
Schmidt, I. (2008), “Krizleri Kiyaslamak 1930'lar, 1970’ler ve Bugün”, Editör William Tabb ve Diğerleri, İçinde Neoliberalizm ve Kriz, Çeviren Barış Baysal ve Diğerleri, Kalkedon Yayınları, 65-77.

Smith, A. (2018), "Illiberal Hegemony: The Trump Administration Strategy for US Imperialism", International Socialist Review, Issue 109, https://isreview.org/issue/109/illiberalhegemony-trump-administration-strategy-us-imperialism (Erişim Tarihi: 08.03.2019).

Stephens, P. (2016), America Can Survive Trump. Not So The West, Financial Times, 10 Nov., https://www.ft.com/content/73313d4c-a68e-11e6-8898-79a99e2a4de6 (Erişim Tarihi: 18.09.2019).

Stiglitz, J.E. (2017), “The Age of Trump, Project Syndicate”, project-syndicate.org/onpoint/theage-of-trump-by-joseph-e-stiglitz-2017-01?barrier=accesspaylog (Erişim Tarihi: 12.10.2019).

Stokes, D (2018), "Trump, American Hegemony And The Future Of The Liberal International Order", International Affairs 94: 1, 133-150. DOI: http://doi.org/10.1093/ia/iix238

Sullivan, J. (2018), “The World After Trump: How The System Can Endure”, Foreign Affairs, Vol. 97, Iss. 2, 10-19. DOI: https://doi.org/10.18778/1641-4233.23.02.

Trump, D. (1987) “I don't Want to be President”: Entire 1987 CNN Interview', in Larry King Live, CNN, 2 September, 1987.

Trump, D. (2017a), Inaugural address, https://www.whitehouse.gov/briefings-statements/theinaugural-address/ (Erişim Tarihi: 13.03.19).

Trump, D. (2017b) Remarks by President Trump at APEC CEO Summit, Da Nang, Vietnam, https://www.whitehouse.gov/briefings-statements/remarks-president-trump-apec-ceosummit-da-nang-vietnam/

Wolf, M. (2017), “The Long and Painful Journey to World Disorder", Financial Times, 5 Jan. https://www.ft.com/content/ef13e61a-ccec-11e6-b8ce-b9c03770f8b1 (Erişim Tarihi: 23.09.2019). 